Marquette University

e-Publications@Marquette

College of Education Faculty Research and

Publications

Education, College of

$2-1-2007$

\title{
Strengthening the Scientific Foundations of Professional Psychology: Time for the Next Steps
}

Timothy Melchert

Marquette University, timothy.melchert@marquette.edu

Accepted version. Professional Psychology: Research and Practice, Vol. 38, No. 1 (February 2007):

34-43. DOI. (C) 2007 American Psychological Association. Used with permission.

This article may not exactly replicate the final version published in the APA journal. It is not the copy of record. 


\section{Strengthening the Scientific Foundations of Professional Psychology: Time for the Next Steps}

Author: Timothy P. Melchert

Abstract: The field of professional psychology has been tremendously successful, although it has also been characterized by many competing preparadigmatic theoretical orientations, which have led to a great deal of contention as well as conflicting views regarding psychological development, functioning, and behavior change. There is now widespread agreement regarding scientific explanations of many psychological processes, however, and, consequently, it is time to update the basic conceptual frameworks used for professional psychology education and practice. Replacing the traditional reliance on an array of theoretical orientations with a sciencebased biopsychosocial framework would resolve many of the contradictions and conflicts that characterized the preparadigmatic era and would also provide a common perspective for unifying psychologists around a shared approach to practice, research, and training.

Few would disagree that both the science and the practice of psychology have enjoyed phenomenal growth and success since their emergence just over a century ago and that the growth of professional psychology during the latter half of that period has been particularly impressive. As early as 1961, E. L. Kelly, the past president of American Psychological Association (APA) Division 12, noted that the growth of clinical psychology was "well nigh phenomenal. Before World War II, clinical psychologists were few in number, poorly paid, and had but little status.... Ours is a success story without counterpart in the history of professions" (p. 9). Since World War II, the number of licensed psychologists in the United States has grown from zero in 1945, when the first psychology licensure law was enacted, to close to 88,500 today (Duffy et al., 2002). Much of the dramatic growth in membership in the APA, which went from 4,173 to over 90,000 during that same period, is also attributable to the large increase in the number of professional psychologists, from a minuscule number before World War II to approximately two thirds of the membership today (APA, 2005b).

Given the youth, reach, and dramatic growth of psychology as a field, it was inevitable that the evolving discipline would experience significant tension and discord and that the science and practice areas in particular would come into conflict, given their differing needs and orientations. At times, the disagreement has been so strong that it is easy to forget that much of the success of professional psychology is directly dependent on the scientific credibility of 
psychology as a discipline, and there is little doubt that the status of professional psychology would crumble if the scientific foundations of the field weakened. Indeed, it is reasonable to expect that the ability of professional psychology to continue to prosper is highly dependent on the extent to which the scientific foundations of the field continue to strengthen.

It is also critical to acknowledge that a large part of the impressive growth of psychology as a scholarly discipline is attributable to the emergence of professional psychology and that psychological science has benefited enormously from the success of professional psychology (Sternberg, 2005). There are now a great many professional psychologists who work in a wide variety of settings, and the field has grown quite visible within health care systems, academia, government, and the public in general. We enjoy large student enrollments at both the undergraduate and the graduate levels, which is vital to our standing within universities. Research funding has grown substantially, and grants are usually awarded for attempts to solve practical problems associated with current mental health and social needs rather than for basic science per se (e.g., most of the funding provided by the National Institute of Mental Health goes to projects that have applied, clinical, or translational purposes; National Institute of Mental Health, 2006).

Although the remarkable growth of psychology has presented many important opportunities, it has also posed significant challenges. In particular, our history has been heavily marked by internecine conflict between camps and schools. The competition and antagonism between the various camps and the "dogma eat dogma" (Larson, 1980, p. 19) environment that characterized much of our history might have subsided somewhat in recent years, but the deep divisions that became evident during the controversy surrounding recovered memories of child abuse and the ongoing contention between those espousing positivist and postmodern viewpoints suggest that the competition and divisions have not yet been resolved. Indeed, many leading psychologists have been concerned that the ongoing fragmentation of the field may affect our continued viability as a scholarly discipline (e.g., Gardner, 2005; Kendler, 2002; Rychlak, 2005; Sternberg, 2005; Driver-Linn, 2003, noted that "perceptions of psychology as beleaguered by fractionation and uncertainty are almost ubiquitous," p. 270).

Partly as an attempt to deal with these various conflicts and controversies, broad consensus has developed over the past several years that psychological practice needs to be based on research evidence regarding the effectiveness of our assessments and interventions (APA, 2005a). This tactic undoubtedly will prove useful for dealing with psychotherapeutic approaches that become controversial, and the reliability of the scientific evidence supporting particular approaches has become a primary focus of the debate in recent controversies 
regarding novel therapy approaches (Chaffin et al., 2006; Herbert \& Gaudiano, 2001; Perkins \& Rouanzoin, 2002; Tsai, Morsbach, \& Loftus, 2003).

Although there may be growing consensus regarding the need for evidence-based practice, it is not yet clear which types of evidence and which criteria must be considered in evaluations of the effectiveness of particular professional practices. For example, as a field, we offer a remarkably wide variety of theoretical orientations for conceptualizing human development, psychopathology, and treatment. Indeed, over 400 different theoretical approaches have been developed (Corsini \& Wedding, 2000). Of course, professional psychology training program faculty do not expect students to learn all of these approaches, but students are usually asked to learn about the most influential ones, which their theories of psychotherapy textbooks often cover chapter by chapter, starting with psychoanalysis and proceeding through humanistic, feminist, narrative, and other, more recent approaches. Students normally learn that these approaches are based on foundational assumptions or first principles that can take remarkably different and irreconcilable perspectives on human nature (e.g., fundamentally conflicted drives in Freudian theory, the blank slate of nearly complete malleability in behaviorism, an optimistic self-actualizing tendency in humanistic theories). These textbooks usually explain that several of these theoretical perspectives address only particular areas of human functioning or have received only limited research examination or inconsistent empirical support.

To help compensate for some of these weaknesses, a variety of eclectic and integrative approaches have also been developed. These generally have also received little systematic empirical examination and are derived from a variety of theoretical starting points (e.g., theory is relatively unimportant in technical eclecticism, integrative approaches often combine two or more of the traditional approaches, and the common factors approach emphasizes still other processes). Students usually receive the message, either explicitly or implicitly, that they must choose one of these theoretical orientations so that their clinical work has structure and direction. Sometimes they make these choices through their decisions about which graduate program to attend and the orientations of the faculty at particular programs. At other times, they choose on the basis of what seems the best fit for them personally or the expectations of an academic advisor.

Compared with other health care professions, this approach to learning the practice of psychology is certainly notable for the latitude allowed for choosing something as fundamental as the theoretical orientation, and consequently several of the particular skills, with which to practice the profession. This approach nonetheless seems to be consistent with the actual 
practice of psychologists. For example, surveys consistently find wide variation in the theoretical orientations of licensed psychologists and other therapists, with substantial numbers endorsing orientations that fundamentally conflict with others. In fact, these surveys usually find that the largest number of adherents to any one particular orientation, even if it is one of several forms of an eclectic or integrative approach, still remains a minority, usually less than one third of the sample (Norcross, 2005). In addition, although there appears to be growing agreement that the field needs to move in the direction of training and assessing the competencies that its students and new practitioners should possess rather than having them merely complete a core curriculum, there seems to be remarkably little agreement about what psychologists should actually be competent to do at anything more than a very general level, such as the ability to do assessment and intervention, but with almost no specificity as to what assessment or intervention actually entails (Kaslow et al., 2004).

These various sources of evidence clearly suggest that professional psychology lacks a shared, common, and systematic approach for conceptualizing our clinical work and, consequently, for preparing students for entry into the profession. The existence of numerous and diverging theoretical orientations also raises questions about the nature of the scientific foundations of the field. When a field lacks a common language and framework for understanding the subject matter involved, it becomes evident that the field may not be based on a particular body of scientific knowledge and associated skills that students and new practitioners are expected to master. Is it then possible that there exist multiple, relatively independent bodies of scientific literature that support a variety of different theoretical orientations for practicing the profession? This article addresses these questions and presents the argument that psychological science has advanced to the point where a unified, sciencebased conceptual framework for professional practice should replace the multifarious assortment of theoretical orientations that have dominated professional psychology throughout our history.

This article proceeds by briefly reviewing the preparadigmatic nature of young sciences before discussing the current scientific status of psychology. It is then argued that a current scientific perspective on human development, functioning, and behavior change conflicts with many of the traditional viewpoints that we still often use for conceptualizing our clinical work as well as our educational programming for preparing future psychologists. Then four propositions are offered for establishing a conceptual framework for the practice of psychology that accommodate and integrate the well-established scientific findings regarding the full range of 
biological, psychological, and sociocultural influences on human development and functioning as well as the full range of evidence-based practices that psychologists currently use.

\section{The Nature of Science and the Scientific Evolution of Psychology}

To understand why professional psychology as well as psychology in general have been characterized by many disconnected and often conflicting approaches to understanding human behavior, it is necessary to remind ourselves about the evolution of scientific disciplines in general. Although a detailed analysis of these issues is well beyond the scope of this article, a brief review is necessary to understand the complicated pattern of development that psychology has followed. This complex history is familiar even to new students to psychology encountering their first courses on personality or psychotherapy. In these classes, they learn about the many highly varied and sometimes conflicting explanations for human behavior that have been offered over the years and the dependence of those explanations on first principles that often have simply been assumed rather than empirically examined and verified. Toulmin (1972), a philosopher of science, described the profusion of different conceptual frameworks in psychology as characteristic of a "would-be" rather than a real academic discipline:

The characteristic features of would-be disciplines can best be illustrated... [when] we turn to professional psychologists [and other social scientists] for explanation of the behaviour of individual human beings... . We find a diversity of approaches of a kind unparalleled in physics... split into parties, factions, or sects, which have not managed to hammer out a common set of disciplinary goals... . And so the factional splitting will continue, justified less by agreed empirical demonstrations than by philosophical appeals to general methodological considerations. (pp. 382-383)

The scientific foundations of psychology obviously have strengthened considerably since Toulmin (1972) offered this description. Nonetheless, the proliferation of theoretical approaches to psychotherapy has continued up to the present. Some recently developed approaches, such as those involving repressed memories of child abuse, eye movement desensitization and reprocessing, thought field therapy, and attachment therapy, quickly became controversial (Brown, Scheflin, \& Hammond, 1998; Chaffin et al., 2006; Herbert \& Gaudiano, 2001; Perkins \& Rouanzoin, 2002). Many others, including several of the eclectic and integrative theoretical models that have been developed recently, have not yet become widely known or undergone thorough empirical examination (Kazdin, 1996; Norcross, 2005).

It is important to note that this type of scientific development is not at all unprecedented. Indeed, young sciences normally are characterized by fragmentation and competition among 
theoretical orientations. For example, when describing the early history of the physical sciences, Kuhn (1962) noted that during the first half of the 18th century

there were almost as many views about the nature of electricity as there were important electrical experimenters... all were components of real scientific theories.... Yet though all the experiments were electrical and though most of the experimenters read each other's works, their theories had no more than a family resemblance. (pp. 13-14)

Battles over the superiority and ownership of ideas were common and frequently fierce, involving scientific giants such as Galileo, Newton, Cavendish, Watt, Lavoisier, and many others (Merton, 1957).

After a lengthy period that included many new, independent discoveries in physics, chemistry, and biology, the ongoing practice of science in those fields over the next decades and even centuries gradually began to uncover more and more relationships between phenomena that at first appeared unrelated. Sometimes scientists noticed that phenomena that intially had seemed completely unconnected were actually different in superficial ways that, in fact, obscured very important, deep relationships between those phenomena (e.g., at first between electrical and magnetic phenomena, later between electricity and chemistry, and still later among electricity, light, and magnetism; Shapere, 1977).

As a young science, psychology over the past 120 years has also been characterized by the development of many independent and competing theories, often with relatively little communication among advocates of the various theories and little attempt to understand the relationships among the approaches. Indeed, the independence of several of these theoretical schools, with their own separate journals, conferences, professional organizations, and academic homes, has continued up to the present. There were some early attempts at identifying linkages among these approaches (French, 1933, and Rosenzweig, 1936, are notable), but these and other important integrative approaches (e.g., Dollard \& Miller, 1950; Frank, 1961) did not stem the flow of new theoretical schools being developed. Eclectic and integrative approaches have become quite influential in the last 3 decades, and several have specifically focused on commonalities and areas of complementarity across theories (e.g., Messer, 1992; Prochaska \& DiClemente, 1984; Wachtel, 1977). It is ironic, however, that we may now be experiencing a proliferation of integrative approaches, which could lead to the repetition of some of the competition and partisanship that gave rise to the integrative movement in the first place (Norcross, 2005). To gain a better understanding of why such a 
variety of theoretical approaches developed, we need to more closely examine the role of scientific paradigms and the nature of the phenomena under study in psychology.

There is substantial agreement among philosophers of science that a mature scientific discipline is characterized by the existence of paradigms that include widely accepted theories, supported by successful and compelling applications of those theories that are taught to students to prepare them for entry into that discipline (Kuhn, 1962; Lakatos, 1970; Laudon, 1977). Many scholars (e.g., Kuhn, 1974; Toulmin, 1972) have pointed out that paradigms have been lacking throughout many of the social sciences, and certainly several areas within psychology have been characterized by multiple, competing views regarding the development of personality and psychopathology as well as methods for changing undesirable behaviors. These areas are characterized as being preparadigmatic.

The research methods that are used to investigate questions at different stages of paradigmatic development also tend to vary. Eysenck (1984) noted that scientific inquiry often begins with hunches, acquired through careful observation and inductive reasoning processes. If the hunch seems reasonable after additional observation and analysis, scientists then specify hypotheses for which they seek verification, perhaps using a combination of correlational and experimental methods. If the verifications of these hypotheses are convincing, a theory might then be developed, and the focus of research at this point generally moves from description to explanation. It is also at this level that Popperian falsification (Popper, 1959) becomes important, with reliance on deductive reasoning and rigorous experimental procedures to examine questions involving mechanisms and causation. Eysenck (1960) described theories that are mainly the focus of verification to be weak, whereas strong theories are those primarily subjected to attempts at falsification. Experimental methods aimed at falsification must be used to demonstrate causation, and, consequently, paradigms cannot be achieved in fields that rely on correlational methods alone (Eysenck \& Eysenck, 1969; Sokal \& Sneath, 1963). If a theory survives sufficient attempts at falsification, it may even be elevated to the status of a scientific law. Kuhn (1962) observed that most of the time spent doing science involves the testing of deductions made within a particular paradigm, with minor improvements then being made to those paradigms as a result. During these periods of "normal science," anomalies are often discovered. If those anomalies eventually can be accounted for by existing theories and laws, the paradigm is consequently strengthened. If they cannot, however, a scientific revolution occurs when it becomes obvious that a new theory is superior at explaining the relevant phenomena. 
The wide variety of research methods currently in use in psychology reflects the rather amazing breadth of topics examined within the discipline as well as the wide range in which they fall in terms of paradigmatic development. In relatively new areas of research, descriptive methods are used to explore hunches about, for example, the influence of the interaction of ethnicity and gender on self-concept or the nature of the cognitive processing used by very highly skilled problem solvers. Several areas in psychophysiology, conversely, have long relied on disconfirmatory experimental methodologies.

Fortunately, there are several fields in psychology that can be considered solidly paradigmatic (indeed, if this were not the case, the claim that professional psychology is a science-based profession would be highly questionable). The science of psychology is clearly much younger and less paradigmatic than the physical sciences, mainly because it is concerned with phenomena that are far more complex than physical phenomena-the noted biologist $\mathrm{E}$. $\mathrm{O}$. Wilson (1998), for example, observed that "by far the most complex systems known to exist in the universe are biological, and by far the most complex of all biological phenomena is the human mind" (p. 81). Naturally, then, it will take longer to reach paradigmatic consensus in psychology than it has in the physical sciences, although this is now happening in many areas.

Several fields within the cognitive neurosciences (including psychophysiology) have a very firm scientific base. There is little disagreement regarding many of the biological substrates underlying the basic aspects of learning, memory, sensation, perception, and emotion (Fanselow \& Poulos, 2005: Kandel, 2006; Thompson, 2005) or the behaviors controlled or mediated by particular brain structures (Friston, 2005; Lezak, 2004). Greater understanding of the biological maturation of the brain, in concert with the findings of developmental psychology, has resulted in a great deal that is now confidently known about the physical, cognitive, and social development of humans across the life span (Gottesman \& Hanson, 2005; Kagan, 2003). The field of health psychology is vast, but there is wide agreement in many areas about the role of behavior in the course of and the treatments for many diseases (Boll, 2004). In the realm of personality, there is widespread consensus regarding the robustness of the Big Five personality traits (i.e., Extraversion, Neuroticism, Conscientiousness, Agreeableness, and Openness; McAdams \& Pals, 2006). Likewise, there is reasonably strong reliability in the classification of many psychiatric diagnoses, although clearly the official nomenclatures remain at the syndromal level because of the lack of validating pathophysiological evidence (American Psychiatric Association, 2000). There is also general agreement regarding a significant genetic component to many psychiatric disorders, although their ultimate phenotypic manifestation is highly dependent on the experience of stressors and other environmental factors (Caspi et al., 2003;

\section{Melchert}


Leonardo \& Hen, 2006). There is little disagreement about the voluminous evidence supporting the effectiveness of psychotherapy (e.g., Lipsey \& Wilson, 1993; Shadish, Navarro, Matt, \& Phillips, 2000; Wampold, 2001), and the magnitude of effects for many psychological interventions has been shown to equal and sometimes exceed that of many medical and psychopharmacological interventions (Barlow, 2004; G. J. Meyer et al., 2001; Hollon, Stewart, \& Strunk, 2006). We also know from fields such as sociology and anthropology as well as from psychology that sociocultural factors exert profound influences on psychological development and functioning, and these factors recently have become fully integrated into psychological models as well (e.g., APA, 2003, 2005a; Greenfield, Keller, Fuligni, \& Maynard, 2003; McAdams \& Pals, 2006; Norenzayan \& Heine, 2005).

At a very fundamental level, there also appears to be no argument that humans are inherently biopsychosocial (BPS) organisms in which the biological, psychological, and social dimensions are inextricably intertwined. Scientists might argue about the importance of particular biological, psychological, or sociocultural ${ }^{1}$ influences on human development and functioning across the life span, but since the publication of Engel's (1977) influential call for a BPS approach to health care in general, consensus has grown around this fundamental perspective (Eysenck, 1997; White, 2005). Although Engel referred to his approach as the "biopsychosocial model," it is important to note that this perspective is not considered a model or a theory because it applies at a very general level and does not attempt to explain specific phenomena related to either physical or mental functioning (Malmgren, 2003; McLaren, 1998). Nonetheless, it does describe an essential and fundamental characteristic of human beings. It is also already very widely accepted, having been established as the foundational perspective for the field of health psychology (Suls \& Rothman, 2004); incorporated into the curricula in nearly all medical schools in the United States and Europe (Frankel, Quill, \& McDaniel, 2003); and officially endorsed by the APA, American College of Obstetricians and Gynecologists, American Nurses Association, National Association of Social Workers, and 22 other health care and social service professional organizations (APA, 2006a). Although other comprehensive, integrative perspectives on human development and functioning have been developed, none enjoys the widespread recognition and acceptance the BPS approach does.

Scientific progress obviously will continue in many areas of psychology, and advances in some areas, such as the cognitive neurosciences, are occurring at a breathtaking pace. In just a few years, perhaps several current hypotheses will move on to become weak theories, and some theories will progress from the weak to the strong category. As we move forward, it is important to acknowledge that biologically oriented research will play an increasingly helpful role 
in providing a unifying perspective for psychology, in particular in terms of the neurosciences and evolutionary theory (Wilson, 1998). Obviously, all of our behavior is dependent on the underlying physiological functioning of the nervous system. As the neurosciences provide more detailed explanations of the neural substrates of cognitive, affective, and behavioral processes, greater familiarity with the physical functioning of the brain will become critical for a complete understanding of psychological development and functioning. An evolutionary perspective is also growing in importance for understanding human behavior. As Buss (1991) explained,

at some fundamental level of description, evolution by natural selection is the process that creates physiological, anatomical, and psychological mechanisms. Therefore the crucial question is not whether evolution is relevant to the understanding of human behavior but how it is relevant. (p. 461)

Adaptation has been described as the central concept for understanding biological development as well as behavioral function at the level of the species, of populations, and of individuals (Holland, 1975; Turkheimer, 1998). Through the ongoing process of adaptation, human beings have evolved with physiological, anatomical, and psychological characteristics that constrain behavior across all the biological, psychological, and sociocultural domains. As several of our traditional psychological theories were founded on assumed first principles about human nature, perhaps explanations of future theories will begin with an evolutionary perspective and a review of the relevant neuroscience findings.

The increasing importance of a biological perspective certainly does not mean that psychology will eventually become a specialty area within biology, just as biology did not become a subfield of chemistry despite how strictly biological processes obey the laws of chemistry and physics. Nor did medicine become a subfield of biology, even though discoveries in microbiology propelled the remarkable advance of allopathic medicine in recent decades. Our genetically inherited evolutionary history obviously constrains our development and behavior in many important ways, but it does not determine our behavior or development, because nearly all psychological outcomes are multifactorially determined, with genetic components interacting so closely with environmental factors that the traditional nature-nurture distinctions are of little value in understanding these processes (i.e., the brain is remarkably plastic and is constantly changing in response to experience; Fanselow \& Poulos, 2005; Gottesman \& Hanson, 2005).

This brief review of the scientific status of psychology is not meant to provide an assessment of the strength of research findings across the various subfields within the discipline. Instead, enough examples of well-accepted scientific findings in psychology are presented so that it is clear that many areas within the field have attained paradigmatic status. The critical 
implication of having reached this point is that we now need to consider replacing the preparadigmatic array of theoretical orientations that have dominated much of our history with a new framework based on current scientific evidence. The need to take this next step becomes clearer when we take a closer look at the theoretical orientations that professional psychologists have often used for conceptualizing their clinical work.

\section{Practitioners' Theoretical Orientations}

Students, educators, and practitioners in professional psychology have grown very used to being asked to identify the theoretical orientation that guides their clinical work. For example, one of the five required essay questions on the standard Association of Psychology Postdoctoral and Internship Centers internship application form asks applicants to "describe your theoretical orientation and describe how this influences your approach to case conceptualization and intervention" (Association of Psychology Postdoctoral and Internship Centers, 2005). The standards for APA accreditation require programs to describe the theoretical perspectives held by the core faculty (Committee on Accreditation, 2005). Insurance providers commonly ask therapists to indicate the theoretical orientation that they ascribe to when they apply to join provider panels, and these are often then advertised to potential clients who are looking for a therapist. At least 36 survey studies have been published that have explored the theoretical orientations endorsed by different types of psychotherapists (Jensen, Bergin, \& Greaves, 1990; Norcross, 2005).

The results of these surveys are widely known. One of the notable results involves the emergence of eclectic and integrative orientations to practice as the most popular approach to guide the professional work of therapists in the last few decades (Norcross, 2005). It is also well known that part of the reason that various psychologists developed eclectic or integrative approaches was the rampant proliferation of schools of therapy during the last half century. A remarkable number of approaches, in excess of 400 , have been developed (Corsini \& Wedding, 2000). Many of these did not receive systematic empirical examination, and many were not endorsed, sometimes not even known, by any sizable number of researchers within the field. As a group, these various theoretical schools described the development of personality and psychopathology and the process of behavior change in a wide variety of ways, which often conflicted with each other, and it is widely known that a number of these theoretical orientations have not fared well in terms of scientific scrutiny. Of course, many psychologists were correct in concluding that this situation was not defensible (e.g., Beutler, 1983; Norcross, 1986). In response, a variety of eclectic and integrative approaches were developed that have been

\section{Melchert}


categorized into approaches focused on technical eclecticism, theoretical integration, common factors, or assimilative integration (Norcross, 2005). These approaches solved some of the obvious problems associated with the proliferation of individual theoretical orientations, but problems remain. The approaches also diverge, sometimes widely, in their theoretical perspectives (e.g., eclecticism vs. theoretical integration vs. common factors), rigorous empirical examination of these approaches has been limited to date, and there has been some proliferation of eclectic and integrative approaches, which then raises questions about their adequacy as a whole (Fishman \& Messer, 2005; Kazdin, 1996; Norcross, 2005).

The limitations of these varied theoretical approaches are understandable given the limited explanations for many mental health issues that have been available until recently. Reliable scientific evidence regarding human psychology has grown quite dramatically over the past couple of decades, however, and, consequently, we may have left the era when individual practitioners could base their clinical case conceptualizations on personal preferences for theoretical orientations. Since the 1990s and the wave of malpractice suits involving repressed memories of child sexual abuse along with the widely publicized client death in the Colorado attachment therapy case, there is now widespread agreement in the mental health care field as well as the legal system that psychological practice must be based on reliable scientific evidence that is appropriately applied to the case at hand-indeed, this is now the official policy of the APA (APA, 2005a).

\section{A Unified Science-Based Approach to Professional Psychology}

Psychological science has advanced to the point where an integrative conceptual framework squarely based on scientific evidence can now replace the traditional assortment of theoretical orientations that characterized the preparadigmatic era within the field. Human development and functioning are incredibly complex (involving the most complex phenomena known to exist), but it is possible to integrate the paradigmatic scientific findings regarding psychology now available through a general but comprehensive conceptual framework. When this is done, I believe we will arrive at at least four basic propositions that would unify the practice of psychology around a shared, common, and scientifically current perspective.

1. Human beings are inherently BPS organisms, and, consequently, psychological practice must be based on an integrative approach to understanding all three of these dimensions. This perspective has a long history, having been introduced into the psychiatry curriculum at Johns Hopkins University almost a century ago (A. Meyer, 1917). More recently, Engel (1977) has been the most influential advocate for the view that humans are inherently

\section{Melchert}


BPS organisms in whom biological, psychological, and social influences on development and functioning are all very influential and, at the same time, inextricably intertwined. Because the BPS perspective is based on one of the most fundamental observations regarding human functioning, it provides an appropriate, useful, and in some ways necessary foundation for conceptualizing the practice of psychology. For example, conceptualizations of the development of personality characteristics, psychopathology, or intelligence obviously fall far short when the influence of culture is not incorporated or biological considerations are ignored. This conclusion would be readily evident to child, medical, family, and geropsychologists, who are routinely faced with the interplay of the biological, psychological, and sociocultural dimensions of their clients' lives in very immediate and direct ways.

2. Psychological assessment procedures must reflect the fundamental BPS nature of human psychology. This proposition actually appears to be well supported by current practices in psychology. For example, a review of popular textbooks for teaching psychological assessment in clinical, counseling, and school psychology finds a high degree of convergence on this point. Whether they are discussing children, adolescents, adults, or seniors, our textbooks are consistent in noting that a variety of biological, psychological, and sociocultural factors must be evaluated and then integrated in formulation of case conceptualizations. It appears that there is a high level of agreement even about many of the details involved, such that one could select almost any one of the popular texts and find guidelines that are generally consistent with the others. Support for this perspective also comes from our ethical guidelines, our licensure exams, and the standards of practice identified by malpractice courts and disciplinary bodies. The Joint Commission on the Accreditation of Healthcare Organizations (2006) behavioral health care standards require that a similar range of domains be assessed, and the practice guidelines published by the American Psychiatric Association (2004) are also consistent with this approach. This convergence of expert opinion reflects the paradigmatic status of the BPS perspective in the field.

An important implication that follows from the necessity of taking a comprehensive, integrative, BPS approach to psychological assessment is that relatively little room is allowed for using personal theoretical orientations when one is conducting these assessments. Information must be collected regarding all the BPS domains and integrated in a rational manner supported by scientific evidence. Certainly, there will be significant variability across practitioners in the information obtained and how it is integrated, but this should occur within reasonable limits. The task of specifying the reasonable limits within which these procedures should be carried out has not yet received a great deal of attention in professional psychology, but medicine has tackled 
these issues repeatedly over the last century (starting with the Flexner Report in 1910; Sharpe \& Faden, 1998), and industrial and organizational psychology has a great deal of experience with similar issues in terms of job analysis and competency modeling (Shippmann et al., 2000). Research findings also cannot yet reliably portion out the variance in many psychosocial outcomes that is attributable to specific BPS influences and their interactions (this is certainly true of medical outcomes as well). Consequently, it is necessary to integrate a great deal of clinical expertise into this process. Nonetheless, our standard guidelines for practice, as they currently exist, require an integrative assessment of all of these domains, and our diagnoses, other assessment findings, and treatment recommendations must follow rationally from a consideration of all of them. One's theoretical preferences do not override these basic requirements.

3. Current evidence suggests more latitude in the process of treatment planning and intervention than in assessment, although they, too, must be based on a BPS approach. Whereas there is broad agreement that psychological assessment must be conducted in a fairly systematic, comprehensive, and integrative BPS manner, currently available evidence suggests that there is a range of treatments that can be recommended for many mental health issues, depending on clients' particular diagnostic, sociocultural, and psychological characteristics, although there are also many syndromes and disorders for which the effective treatments appear to be circumscribed. The wide range of issues that psychologists treat makes it difficult to generalize on this point, although, again, an examination of popular textbooks and other resources reveals substantial agreement with regard to many aspects of treatment planning.

As is the case with assessment, however, one has limited latitude with regard to recommending treatments that are based on one's personal theoretical orientation rather than the client's BPS needs, circumstances, and preferences, along with what research evidence supports. As is the case with assessment, clinical expertise plays an important role when one is recommending treatments to any given client, but the obligation to approach treatment planning on the basis of an assessment of clients' needs and BPS circumstances, along with the evaluation of treatment risks, benefits, and alternatives, is very clear, as are the prohibitions against imposing one's theoretical or other biases on clients and against losing one's ability to remain reasonably objective throughout this process (APA, 2002; Beauchamp \& Childress, 2001).

4. Mental health practitioners specialize. Clearly, practitioners have particular strengths, weaknesses, competencies, and preferences when it comes to their professional work, but their scope of practice is properly conceptualized as a specialization rather than a theoretical

\section{Melchert}


orientation, as we have often viewed it. The argument here is that one must conceptualize cases from a BPS perspective if one's practice is going to be appropriately science based, although one is certainly free to specialize in working with particular types of treatments or populations. For example, because of prior education, supervised experience, preferences, and market forces, psychologists typically specialize in providing particular types of treatments with certain types of populations. If one typically works with adults with common Axis I and II issues and provides treatments that include popular evidence-based approaches, this might properly be conceptualized as adult general practice psychology. If, however, one offers only a particular type of therapy or works with only particular issues or populations, one's practice might best be viewed as a specialization. In many areas of professional psychology, definitions for different types of practices have been developed (for a listing of specialties and proficiencies currently recognized by the APA, see APA, 2006b). The definition of general practice psychology and its associated competencies has received less attention, however. I now turn to this and other implications that follow from the above propositions.

\section{Implications for Professional Psychology Practice, Education, and Research}

Because of the fundamentally complex BPS nature of human beings, there appears to be no scientifically supported alternative but to take a comprehensive, integrative approach to understanding human psychology. Any individual, a group of individuals, or the species as a whole cannot be fully understood without an integration of each of these perspectives. Using such an approach is conceptually very complex, and attempting to unify the field around a common conceptual framework would involve significant challenges to existing conventions. Nonetheless, we are obligated to consider adopting such an approach, because ours is a science-based profession. Below is an initial discussion of some of the challenges and benefits that would follow from adopting the above proposals. These issues often overlap across the categories of practice, education, and research, but these categories are useful for organizing the discussion.

\section{Practice}

As noted above, taking a BPS approach would not require changes in many of our current actual practices involving assessment, treatment planning, and intervention, because many of these practices are already based on a comprehensive, integrative, BPS, evidencebased approach. Some of the language and frameworks used for conceptualizing psychological practice, however, would need to change. The language of theoretical orientations would generally be replaced by references to competencies and specializations, and the terms theory 
and theoretical orientation would increasingly be used in their scientific sense rather than in the popular sense, which can refer to a hypothesis or even a conjecture. Students entering the field would learn that the theoretical orientation that will guide their practice involves a comprehensive, integrative approach that is squarely based on available scientific evidence and that neglecting to take this approach can result in incomplete case conceptualizations, misdiagnosed problems, and incomplete or ineffective treatment plans. Certainly, many practitioners would continue to specialize in providing particular types of treatments, but taking a BPS perspective would mean that they would not refer to their expertise with particular treatments as a theoretical orientation.

Taking this approach would also push us away from practicing particular types of therapy and instead toward practicing psychology. I argue that practicing psychology requires a comprehensive, integrative perspective, whereas conducting one of the popular types of therapy (e.g., psychodynamic, cognitive, family systems, or eclectic therapy) involves the use of a particular framework that supports the implementation of that type of therapy. Therefore, one would use a cognitive-behavioral therapy framework to perform cognitive-behavioral therapy but not as the theoretical orientation with which to conduct a psychological assessment and develop a treatment plan.

Many specialists, such as those practicing child psychology, health psychology, neuropsychology, or geropsychology, are already taking an explicitly comprehensive BPS approach that is fully integrative and often involves the participation of a multidisciplinary team. Consequently, we already have many models for how this is done (see also Sperry, 2001). Focusing on the practice of psychology (as opposed to therapies) is also inclusive of the types of practices that these and other psychologists already engage in and that sometimes involve little psychotherapy (Barlow, 2004). It is useful to remember as well that practicing psychology, as opposed to practicing therapies, is what our professional licenses actually permit us to do.

\section{Education}

Taking a science-based BPS approach to professional psychology education would require major changes in some areas but relatively minor changes in others. As noted above, training in psychological assessment procedures, for example, may require relatively little change. Other educational practices would evolve significantly, however. Emphasizing the practice of psychology rather than the theoretical orientation one uses to perform a particular therapy immediately raises questions about the type of practice involved. It then becomes necessary to address the definition of general practice psychology and its relation to the common specializations, several of which have already been officially delineated (APA, 2006b). 
A definition of general practice psychology needs to be formulated before it is possible to identify the specific assessment, intervention, and other competencies that are necessary for students preparing to enter that type of practice. The APA accreditation standards currently require that accredited professional psychology graduate and internship training programs provide education that is "broad and general preparation for practice at the entry level" (Committee on Accreditation, 2005, p. 5). "Broad and general" practice, however, is not further defined. Doing so would have implications for the range of assessment procedures, treatments, and populations in which one should demonstrate competence to engage in general psychological practice. This would then have implications for the types of classroom, practicum, and internship training experiences that students would complete as well as for the nature and sequencing of any specialized training that they might also complete.

The assessment and accreditation of educational programs in the United States in general has shifted to a competencies-based approach, as opposed to a core curriculum approach, over the last 15 years (Nichols \& Nichols, 2001). This requires that sets of competencies be identified before the assessment or accreditation review can take place. Organizing professional psychology around the practice of therapies makes it quite difficult to develop standardized approaches for assessing readiness for internship or licensure, because someone could be fully competent at conducting cognitive therapy, for example, but incompetent with regard to the general practice of psychology if he or she is not competent with a BPS approach to assessment and treatment planning with some range of populations. (The extent to which the inverse is true, however, is less clear.) Identifying what the practice of psychology entails at the general practitioner and specialized levels is essentially prerequisite to establishing standardized approaches to assessing competence to practice psychology. Doing so would then have ramifications for internship and licensure application procedures, which could begin requiring formal, standardized assessments of the competencies needed for particular types of practice or at least endorsements by those who could take responsibility for judging these competencies.

Emphasizing a BPS approach to professional psychology education might also result in stronger preparation in the scientific foundations of psychology than what is now typically required. Of course, changing curricula can be a very complex undertaking, but embracing a BPS approach might make it obvious that certain areas need to receive more attention than they often currently do for students to gain sufficient grounding in the biological, psychological, and sociocultural foundations of behavior.

\section{Research}

17 Melchert 
Truly embracing a BPS approach to professional psychology would significantly increase practitioners' dependence on the scientific basis for their work. The often repeated criticism regarding the irrelevance of psychological science to practice will weaken as the breadth of the paradigmatic psychological knowledge we now have is more fully appreciated. Taking a BPS approach will also reduce the competition that has marked our history among the advocates of different schools, theories, and research methodologies and among those emphasizing biological, psychological, or social influences on behavior. If we are to take the next steps in the development of psychology as a science and a practice, it would be very helpful to bring together the various camps and schools around a shared conceptual framework, in part so that energies now spent on competition and partisanship instead can be invested in moving the field forward. For example, arguments between advocates of quantitative and qualitative research methodologies have become quite divisive for the field (Rychlak, 2005). When a comprehensive BPS approach is endorsed, however, it becomes difficult to argue that quantitative neuroscience "bench research" is irrelevant if it is focused on understanding important brain mechanisms. Likewise, it becomes difficult to criticize qualitative research involving, for example, ethnographies designed to uncover universal psychological attributes shared by humans across cultures. A more pluralistic appreciation for the full range of exploratory, correlational, and disconfirmatory research methodologies will develop when the commitment to understanding the complex, interrelated, BPS nature of human psychology is strengthened.

In an evidence-based BPS approach to practice, one chooses the interventions that are most likely to be effective on the basis of the question at hand, not the interventions one happens to have been trained in or knows the best. Likewise, in an evidence-based BPS approach to science, one selects research methods on the same basis. Taking this approach will help orient the field toward problems and phenomena to be understood and away from camps devoted to researching particular topics using their preferred conceptualizations or familiar methodologies, a tendency that can impede scientific progress (Sternberg \& Grigorenko, 2001).

\section{Conclusion}

It is time for us to move away from the preparadigmatic era in professional psychology. That era truly was remarkably successful in terms of both science and practice, but current scientific evidence no longer supports choosing from a selection of theoretical orientations for guiding one's approach to psychological practice. The amount of widely accepted knowledge in the tremendously complex and young field of psychology was limited until recently, but this is no 
longer the case, and there is now widespread agreement regarding the adequacy of explanations for many aspects of psychological development and functioning.

Updating the basic frameworks that we use to conceptualize psychological practice is obviously a major and serious undertaking, but the continued development of the profession requires that our practice guidelines and educational curricula are scientifically current. Current scientific knowledge regarding human development and functioning clearly points to a comprehensive, integrative conceptual framework that can accommodate the highly complex and integrated BPS nature of human beings. The BPS approach, advocated by Engel (1977) 30 years ago, has become widely known and accepted by the health care professions because it satisfies these requirements. Consequently, it is a good candidate for replacing the myriad theoretical orientations that have resulted in numerous contradictions and conflicts for professional psychology over the years.

For those not already using a BPS framework in their practice, embracing this type of conceptual framework could be very challenging. The amount of work involved in developing new training and practice guidelines for implementing this type of approach is also daunting. Unifying psychologists around a common, science-based perspective, however, would have major benefits, among which is the potential to develop a much more unified voice for applying psychological research and practice to the extremely important mental health and social issues faced by societies around the world. Given that ours is a science-based profession, it appears that we cannot avoid the question of whether recent scientific progress requires that we now take these next steps in strengthening the scientific foundations of the profession.

\section{References}

American Psychiatric Association (2000). Diagnostic and statistical manual of mental disorders (4th ed., text rev.). Washington, DC: Author.

American Psychiatric Association (2004). American Psychiatric Association practice guidelines for the treatment of psychiatric disorders. Arlington, VA: Author.

American Psychological Association (2002). Ethical principles of psychologists and code of conduct. American Psychologist, 57, 1060-1075.

American Psychological Association (2003). Guidelines in multicultural education, training, research, practice, and organizational change for psychologists. American Psychologist, 58, 377-402. 
American Psychological Association (2005a). American Psychological Association policy statement on evidence-based practice in psychology. Retrieved May 6, 2006, from http://www2.apa.org/practice/ebpstatement.pdf

American Psychological Association (2005b). APA members by membership status. Retrieved May 6, 2006, from http://researchapa.org/profile2005t3.pdf

American Psychological Association (2006a). Health Care for the Whole Person statement of vision and principles. Retrieved May 2, 2006, from http://www.apa.org/practice/hcwp_statement.html

American Psychological Association (2006b). Specialties and proficiencies in professional psychology Retrieved September 2, 2006, from www.apa.org/crsppp.rsp.html Association of Psychology Postdoctoral and Internship Centers (2005). Uniform application. Retrieved May 6, 2006, from http://www.appic.org/downloads/AAPI2006-07.doc

Barlow, D. H. (2004). Psychological treatments. American Psychologist, 59, 869-878.

Beauchamp, T. L., Childress, J. F. (2001). Principles of biomedical ethics (5th ed.). New York: Oxford University Press.

Beutler, L. E. (1983). Eclectic psychotherapy: A systematic approach. New York: Pergamon. Boll, T. (Ed.) (2004). Handbook of clinical health psychology. Washington, DC: American Psychological Association.

Brown, D., Scheflin, A. W., Hammond, D. C. (1998). Memory, trauma treatment, and the law. New York: Norton.

Buss, D. M. (1991). Evolutionary personality psychology. Annual Review of Psychology, 42, 459-491.

Caspi, A., Sugden, K., Moffitt, T. E., Taylor, A., Craig, I. W., Harrington, H., et al. (2003, July 18). Influence of life stress on depression: Moderation by a polymorphism in the 5-HTT gene. Science, 301, 386-389

Chaffin, M., Hanson, R., Saunders, B. E., Nichols, T., Barnett, D., Zeanah, C., et al. (2006). Report of the APSAC Task Force on Attachment Therapy, Reactive Attachment Disorder, and Attachment Problems. Child Maltreatment, 11, 76-89.

Committee on Accreditation (2005). Guidelines and principles for accreditation of programs in professional psychology. Washington, DC: American Psychological Association.

Corsini, R. J., Wedding, D. (2000). Current psychotherapies (6th ed.). Itasca, IL: Peacock.

Dollard, J., Miller, N. E. (1950). Personality and psychotherapy. New York: McGraw-Hill.

Driver-Linn, E. (2003). Where is psychology going? Structural fault lines revealed by psychologists' use of Kuhn. American Psychologist, 58, 269-278.

20 Melchert 
Duffy, F. F., West, J. C., Wilk, J., Narrow, W. E., Hales, D., Thompson, J., et al. (2002). Chapter 21: Mental health practitioners and trainees. Retrieved May 2, 2006, from the Substance Abuse and Mental Health Services Administration Web site: http://www.mentalhealth.samhsa.gov/publications/allpubs/SMA04-3938/Chapter21.asp

Engel, G. L. (1977, April 8). The need for a new medical model: A challenge for biomedicine. Science, 196, 129-136.

Eysenck, H. J. (1960). The place of theory in psychology. In H. J. Eysenck (Ed.), Experiments in personality (pp. 305-315). London: Routledge \& Kegan Paul.

Eysenck, H. J. (1984). The place of individual differences in a scientific psychology. In J. Royce \& L. Moos (Eds.), Annals of theoretical psychology (pp. 17-114). New York: Plenum Press.

Eysenck, H. J. (1997). Personality and experimental psychology: The unification of psychology and the possibility of a paradigm. Journal of Personality and Social Psychology, 73, 1224-1237.

Eysenck, H. J., Eysenck, S. B. G. (1969). Personality structure and measurement. London: Routledge \& Kegan Paul.

Fanselow, M. S., \& Poulos, A. M. (2005). The neuroscience of mammalian associative learning. Annual Review of Psychology, 56, 207-234.

Fishman, D. B., \& Messer, S. B. (2005). Case-based studies as a source of unity in applied psychology. In R. J. Sternberg (Ed.), Unity in psychology: Possibility or pipedream? (pp. 37-59). Washington, DC: American Psychological Association.

Frank, J. D. (1961). Persuasion and healing. Baltimore: Johns Hopkins University Press.

Frankel, R. M., Quill, T. E., McDaniel, S. H. (Eds.) (2003). The biopsychosocial approach: Past, present, and future. Rochester, NY: University of Rochester Press.

French, T. M. (1933). Interrelations between psychoanalysis and the experimental work of Pavlov. American Journal of Psychiatry, 89, 1165-1203.

Friston, K. J. (2005). Models of brain function in neuroimaging. Annual Review of Psychology, $56,57-87$.

Gardner, H. (2005). Scientific psychology: Should we bury it or praise it? In R. J. Sternberg (Ed.), Unity in psychology: Possibility or pipedream? (pp. 77-90). Washington, DC: American Psychological Association.

Gottesman, I. I., \& Hanson, D. R. (2005). Human development: Biological and genetic processes. Annual Review of Psychology, 56, 263-286. 
Greenfield, P. M., Keller, H., Fuligni, A., \& Maynard, A. (2003). Cultural pathways through universal development. Annual Review of Psychology, 54, 461-490.

Herbert, J. D., \& Gaudiano, B. A. (2001). The search for the Holy Grail: Heart rate variability and thought field therapy. Journal of Clinical Psychology, 57, 1207-1214.

Holland, J. (1975). Adaptation in natural and artificial systems. Ann Arbor: University of Michigan Press.

Hollon, S. D., Stewart, M. O., \& Strunk, D. (2006). Enduring effects for cognitive behavior therapy in the treatment of depression and anxiety. Annual Review of Psychology, 57, 285-315.

Jensen, J. P., Bergin, A. E., \& Greaves, D. W. (1990). The meaning of eclecticism: New survey and analysis of components. Professional Psychology: Research and Practice, 2, 124130.

Joint Commission on the Accreditation of Healthcare Organizations (2006). Comprehensive accreditation manual for behavioral health care. Oakbrook Terrace, IL: Author.

Kagan, J. (2003). Biology, context, and developmental inquiry. Annual Review of Psychology, $54,1-23$.

Kandel, E. R. (2006). In search of memory: The emergence of a new science of mind. New York: Norton.

Kaslow, N. J., Borden, K. A., Collins, F. L., Forrest, L., Illfelder-Kaye, J., Nelson, P. D., et al. (2004). Competencies conference: Future directions in education and credentialing in professional psychology. Journal of Clinical Psychology, 60, 699-712.

Kazdin, A. E. (1996). Combined and multimodal treatments in child and adolescent psychotherapy: Issues, challenges, and research directions. Clinical Psychology: Science and Practice, 3, 69-100.

Kelly, E. L. (1961). Clinical psychology-1960. Report of survey findings. Newsletter: Division of Clinical Psychology of the American Psychological Association, 14, 1-11.

Kendler, H. W. (2002). Romantic versus realistic views of psychology. American Psychologist, 57, 1125-1126.

Kuhn, T. S. (1962). The structure of scientific revolutions. Chicago: University of Chicago Press.

Kuhn, T. S. (1974). The structure of scientific revolutions (2nd ed.). Chicago: University of Chicago Press.

Lakatos, I. (1970). Falsification of the methodology of scientific research programmes. In I. Lakatos \& A. Musgrave (Eds.), Criticism and the growth of knowledge (pp. 19-129). Cambridge, England: Cambridge University Press. 
Larson, D. (1980). Therapeutic schools, styles, and schoolism: A national survey. Journal of Humanistic Psychology, 20, 3-20.

Laudon, L. (1977). Progress and its problems. Berkeley: University of California Press.

Leonardo, E. D., \& Hen, R. (2006). Genetics of affective and anxiety disorders. Annual Review of Psychology, 57, 117-137.

Lezak, M. (2004). Neuropsychological assessment. New York: Oxford University Press.

Lipsey, M. W., \& Wilson, D. B. (1993). The efficacy of psychological, educational, and behavioral treatment: Confirmation from meta-analysis. American Psychologist, 48, 1181-1209.

Malmgren, H. (2003). The theoretical basis of the biopsychosocial model. In P. White (Ed.), Biopsychosocial medicine: An integrated approach to understanding illness (pp. 21-35). Oxford, England: Oxford University Press.

McAdams, D. P., \& Pals, J. L. (2006). A new Big Five: Fundamental principles for an integrative science of personality. American Psychologist, 61, 204-217.

McLaren, N. (1998). A critical review of the biopsychosocial model. Australian and New Zealand Journal of Psychiatry, 32, 86-92.

Merton, R. K. (1957). Priorities in scientific discovery. American Sociological Review, 22, 635659.

Messer, S. B. (1992). A critical examination of belief structures in integrative and eclectic psychotherapy. In J. C. Norcross \& M. R. Goldfried (Eds.), Handbook of psychotherapy integration (pp. 130-168). New York: Basic Books.

Meyer, A. (1917). Progress in teaching psychiatry. Journal of the American Medical Association, 69, 861-863.

Meyer, G. J., Finn, S. E., Eyde, L. D., Kay, G. G., Moreland, K. L., Dies, R. R., et al. (2001). Psychological testing and psychological assessment: A review of evidence and issues. American Psychologist, 56, 128-165.

National Institute of Mental Health(2006). Strategic plans and priorities. Retrieved May 2, 2006, from http://www.nimh.nih.gov/strategicplanmenu.cfm

Nichols, J. O., Nichols, K. W. (2001). General education assessment for improvement of student academic achievement: Guidance for academic departments and committees. New York: Agathon Press.

Norcross, J. C. (1986). Eclectic psychotherapy: An introduction and overview. In J. C. Norcross (Ed.), Handbook of eclectic psychotherapy (pp. 3-24). New York: Brunner/Mazel. 
Norcross, J. C. (2005). A primer on psychotherapy integration. In J. C. Norcross \& M. R. Goldfried (Eds.), Handbook of psychotherapy integration (2nd ed., (pp. 3-23). New York: Oxford University Press.

Norenzayan, A., \& Heine, S. J. (2005). Psychological universals: What are they and how can we know? Psychological Bulletin, 131, 763-784.

Perkins, B. R., \& Rouanzoin, C. C. (2002). A critical evaluation of current views regarding eye movement desensitization and reprocessing (EMDR): Clarifying points of confusion. Journal of Clinical Psychology, 58, 77-97.

Popper, K. (1959). The logic of scientific discovery. New York: Basic Books.

Prochaska, J. O., DiClemente, C. C. (1984). The transtheoretical approach: Crossing the traditional boundaries of therapy. Homewood, IL: Dow Jones-Irvin.

Rosenzweig, S. (1936). Some implicit common factors in diverse methods in psychotherapy. American Journal of Orthopsychiatry, 6, 412-415.

Rychlak, J. F. (2005). Unification in theory and method: Possibilities and impossibilities. In R. J. Sternberg (Ed.), Unity in psychology: Possibility or pipedream? (pp. 145-158). Washington, DC: American Psychological Association.

Shadish, W. R., Navarro, A. M., Matt, G. E., \& Phillips, G. (2000). The effects of psychological therapies under clinically representative conditions: A meta-analysis. Psychological Bulletin, 126, 512-529.

Shapere, D. (1977). Scientific theories and their domains. In F. Suppe (Ed.), The structure of scientific theories (2nd ed., (pp. 518-565). Urbana: University of Illinois Press.

Sharpe, V. A., Faden, A. I. (1998). Medical harm: Historical, conceptual, and ethical dimensions of iatrogenic illness. Cambridge, England: Cambridge University Press.

Shippmann, J. S., Ash, R. A., Battista, M., Carr, L., Eyde, L. D., Hesketh, B., et al. (2000). The practice of competency modeling. Personnel Psychology, 53, 703-740.

Sokal, R., Sneath, H. (1963). Principles of numerical taxonomy. London: Freeman.

Sperry, L. (2001). Integrative and biopsychosocial therapy. Alexandria, VA: American Counseling Association.

Sternberg, R. J. (2005). Unifying the field of psychology. In R. J. Sternberg (Ed.), Unity in psychology: Possibility or pipedream? (pp. 3-14). Washington, DC: American Psychological Association.

Sternberg, R. J., \& Grigorenko, E. L. (2001). Unified psychology. American Psychologist, 56, 1069-1079. 
Suls, J., \& Rothman, A. (2004). Evolution of the biopsychosocial model: Prospects and challenges for health psychology. Health Psychology, 23, 119-125.

Thompson, R. F. (2005). In search of memory traces. Annual Review of Psychology, 56, 1-23.

Toulmin, S. E. (1972). Human understanding. Oxford, England: Oxford University Press.

Tsai, A. C., Morsbach, S. K., \& Loftus, E. F. (2003). In search of recovered memories. In W. T.O'Donohue \& E. R. Levensky (Eds.), Handbook of forensic psychology: Resource for mental health and legal professionals (pp. 555-577). London: Academic Press.

Turkheimer, E. (1998). Heritability and biological explanation. Psychological Review, 105, 782791.

Wachtel, P. L. (1977). Psychoanalysis and behavior therapy: Toward integration. New York: Basic Books.

Wampold, B. E. (2001). The great psychotherapy debate: Models, methods, and findings. Mahwah, NJ: Erlbaum.

White, P. (2005). Biopsychosocial medicine: An integrated approach to understanding illness. New York: Oxford University Press.

Wilson, E. O. (1998). Consilience: The unity of knowledge. New York: Knopf.

\section{Footnotes}

1 Social and sociocultural are used interchangeably in this article. The popular term biopsychosocial has obviously relied on the word social for the last 3 decades, although sociocultural is often preferred because of its emphasis on culture as a particularly important social factor. 